\title{
Gas flow dynamics in the conduit of Strombolian explosions inferred from seismo-acoustic observations at Aso volcano, Japan
}

\author{
Kyoka Ishii ${ }^{1,2^{*}}$ (D) Akihiko Yokoo ${ }^{2}$, Tsuneomi Kagiyama ${ }^{2}$, Takahiro Ohkura², Shin Yoshikawa ${ }^{2}$ and Hiroyuki Inoue ${ }^{2}$
}

\begin{abstract}
Strombolian explosions are one of the most studied eruptive styles and are characterized by intermittent explosions. The mechanism of a Strombolian explosion is modeled as a large gas pocket (slug) migrating through the magma conduit and then bursting at the air-magma interface. These ascending and bursting processes of the slug induce characteristic seismo-acoustic signals during each explosion: very-long-period (VLP) seismic signals, eruption earthquake signals, and infrasound signals. However, at Stromboli volcano, it has been reported that the ascent velocity estimated from the time differences between observed signals is nearly an order of magnitude higher than that expected from laboratory experiments simulating slug ascent. This discrepancy between observation-based and experiment-based velocities has not yet been fully explained and strongly suggests that the conventional model of Strombolian explosions should be partially revised. In this study, we attempted to validate the model of Strombolian explosions by estimating the gas phase velocity in the conduit in the case of Aso volcano. We recorded seismo-acoustic signals accompanying Strombolian events at Aso volcano, Japan, in late April 2015 via our monitoring network, and the ascent velocity of the gas phase was determined from the difference in arrival times between the VLP signals and the infrasound signals. Our estimated velocity exceeded $100 \mathrm{~m} / \mathrm{s}$, which is much faster than the experimental value of $7.5 \mathrm{~m} / \mathrm{s}$ predicted for Aso volcano. To explain this rapid ascent velocity, we propose a revised model describing the migration of the gas phase via a more complicated mechanism, such as annular flow. In this model, we assumed that the gas phase ascends in the conduit at high velocity while making a pathway leading to the magma surface, most likely due to a temporary increase in the gas flux. Our model will help to deepen the understanding of the complicated dynamics in the magma conduit during a Strombolian explosion.
\end{abstract}

Keywords: Strombolian explosion, Aso volcano, Slug ascent velocity, Seismo-acoustic signals

\section{Introduction}

Strombolian explosions are one of the most famous eruption styles at volcanoes associated with basaltic to basaltic andesite magmatic systems. They consist of repeated small explosions with instantaneous ejection of gas and magma fragments (Patrick et al. 2007). Over several decades, multiple surveillance

\footnotetext{
${ }^{*}$ Correspondence: ishii.kyoka.46m@st.kyoto-u.ac.jp

${ }^{2}$ Aso Volcanological Laboratory, Kyoto University, 3028 Sakanashi,

Ichinomiya-machi, Aso, Kumamoto 869-2611, Japan

Full list of author information is available at the end of the article
}

techniques typified by seismo-acoustic and imaging observations have been employed near vents at some active volcanoes with Strombolian explosions, including the volcanoes Stromboli, Yasur, and Erebus, to investigate the eruptive and degassing processes (e.g., Blackburn et al. 1976; Braun and Ripepe 1993; Nabyl et al. 1997; Rowe et al. 2000). Based on the results, Strombolian explosions have been described as bursting gas pockets that generate seismic and infrasound signals (e.g., Ripepe et al. 2001). In recent years, the study of Strombolian explosions has attained a stage where more rigorous and universal understanding is 
required. The development of observation and analysis techniques has contributed to the identification of explosion-related phenomena, such as ground deformation starting $200 \mathrm{~s}$ before an explosion (Genco and Ripepe 2010), supersonic gas emission (Marchetti et al. 2013; Genco et al. 2014), and fluctuations in the velocity history of pyroclasts (Taddeucci et al. 2012). Furthermore, Gaudin et al. (2017) systematically classified many Strombolian-style activities over a wide range of variations in magnitude and erupted products at four volcanoes.

The dynamics of Strombolian explosions have been described simply as the bursting of a large gas bubble (called a "slug") that has risen in a magma conduit from depth. This idea was proposed based on the results of both field observations and analog experiments (Blackburn et al. 1976; Jaupart and Vergniolle 1989) and remains widely accepted today. In terms of where gas accumulation occurs within the magmatic system, there are two primary models: the rise speed dependent model (RSD model; Wilson 1980; Wilson and Head 1981) and the collapsing foam model (CF model; Jaupart and Vergniolle 1988, 1989). In the RSD model, a larger bubble overtakes and absorbs smaller bubbles in magma during the ascent process in the conduit because the ascent velocity of a large bubble is higher than that of a small bubble. In contrast, in the CF model, gas bubbles accumulate and collapse into a slug at a structural barrier, such as the roof of the magma chamber or a constriction in the conduit. James et al. (2013) proposed a model combining both models because neither of the two idealized conduit geometries (RSD: a long, uniform vertical conduit; CF: a flat, horizontal magma chamber roof) represents a natural system. In this combined model, cascading foam collapse events effectively convert a steady gas flux into an unsteady output flux. Therefore, the foam collapse process might be important for Strombolian explosions, and the CF model may simplify this process in an appropriate manner. In fact, at Etna, it is suggested that gas bubbles might accumulate at a given depth (Allard et al. 2005) and that the CF model is more suitable (Vergniolle and Ripepe 2008).

Seismo-acoustic signals typically observed in association with each Strombolian explosion are thought to be generated from phenomena associated with slug dynamics (Harris and Ripepe 2007). A very-longperiod (VLP) seismic signal preceding the explosion is interpreted as the generation of the slug at the base of the conduit and/or the migration of the gas slug in the conduit (Ripepe et al. 2001; Chouet et al. 2003). Subsequently, the slug reaches the surface of the magma and bursts, creating eruption earthquakes and infrasound signals (Braun and Ripepe 1993; Harris and Ripepe
2007). These seismo-acoustic signals can be used to constrain the depth of the bursting point inside the conduit and the ascent velocity of the slug (Ripepe et al. 2001).

However, the ascent velocity of the slug estimated from seismo-acoustic signals is one order of magnitude faster than the values expected from theoretical and experimental considerations (Harris and Ripepe 2007; Gurioli et al. 2014). At Stromboli volcano, the time difference between the signal arrivals has led to estimates of $10-70 \mathrm{~m} / \mathrm{s}$ and $13-25 \mathrm{~m} / \mathrm{s}$ (Harris and Ripepe 2007; Gurioli et al. 2014). In contrast, the theoretical and experimental equations of Batchelor (1967) and Viana et al. (2003) predict slower velocities of 1.5-3.4 and $0.11-2.6 \mathrm{~m} / \mathrm{s}$. At present, no good explanations are available to account for this discrepancy. This fact suggests that, from the perspective of the CF model, the flow of the gas phase in the conduit is more complicated than the simple ascent of a single slug.

In recent studies, some researchers have developed models of gas flow in the conduit during Strombolian explosions. From a material analysis of ejecta produced by explosions, Gurioli et al. (2014) proposed that a layer of high-viscosity materials composed of recycled ejected magma fragments is present in the upper part of the conduit. This layer makes the rising gas flow more complex than a single slug (Del Bello et al. 2015; Capponi et al. 2016, 2017). However, the existence of this layer cannot contribute to the acceleration of the gas ascent velocity in the calculation (Lieth and Hort 2016). On the other hand, Goto et al. (2014) proposed that the slug might consist of numerous microbubbles that subsequently burst during an explosion. This hypothesis is based on the presence of a high-frequency acoustic signal recorded by wideband microphones. A similar idea was proposed by Taddeucci et al. (2012) and Gaudin et al. (2014), who reported ejection pulses of projectiles and noted that a Strombolian explosion consists of multiple pulses, not a single explosion. Hence, the gas flow in the conduit might be interpreted not as the ascent of a single slug but as a sequence of shortly separated transient gas pockets. In this case, the flow dynamics of the gas phase in the conduit are absolutely different from those of an ascending slug.

In this study, we aim to understand the gas flow dynamics in the conduit during a Strombolian explosion from the perspective of the CF model by investigating the velocity of the ascending gas. We used seismo-acoustic signals of 381 Strombolian events at Aso volcano in Japan to estimate the ascent velocity. Then, we compared this velocity with an experiment-based value (Viana et al. 2003). From the results of these analyses, we argue that a revised model is needed to describe how the gas phase rises in the conduit during explosions. 


\section{Aso volcano and the 2014-2015 eruption}

Aso (Nakadake) volcano is located inside the $25 \times 18 \mathrm{~km}$ Aso caldera in central Kyushu (southwestern Japan; Fig. 1a), which formed through a series of four eruptions accompanied by gigantic pyroclastic flows from 270 to $90 \mathrm{ka}$. More than 17 postcaldera volcanoes are located inside the caldera (Fig. 1b). According to historical records, Nakadake is the only volcano that has been active since the ninth century (Ono et al. 1995). Nakadake volcano has several N-S-aligned craters in the summit area (Fig. 1c). For the last few decades, the northernmost crater has exhibited 10- to 20-year cycles of eruption activity, with each cycle composed of three main stages (Yoshikawa and Sudo 2004): (1) a calm stage with a crater lake, (2) a preparation stage with a dried-up crater and glowing vents, and (3) an active stage characterized by Strombolian explosions.

The latest magmatic eruptions began on 25 November 2014 after a 22-year hiatus (Yokoo and Miyabuchi 2015) and lasted until May 2015. Prior to the start of the 2014-2015 eruptions, the amount of acidic hot water in the crater lake began to decrease in late 2012 and entirely disappeared in December 2013 (Ichimura et al. 2018). Similar to the typical activity that has occurred over the past 1100 years (Ono et al. 1995), the 2014-2015 eruptive cycle was characterized mostly by continuous ash emission and frequent Strombolian explosions. The Strombolian explosions that did occur in the 2014-2015 eruption ejected incandescent lapilli from an eruptive vent (diameter of $\sim 50 \mathrm{~m}$, Fig. 2a) located in the center of the crater. This process led to the formation of a pyroclastic cone. Magma fragments from the Strombolian explosions often reached $>200 \mathrm{~m}$ above the crater rim.

\section{Observation and data}

In this study, the 2014-2015 eruption of Aso volcano was monitored by a seismo-acoustic network composed of six seismic and four infrasound stations (Fig. 1c; refer to Additional file 1). Half of the seismic stations, i.e., KAF, KAK, and SUN, were equipped with short-period seismometers (flat response for $>1.5 \mathrm{~Hz}$ ). The others, i.e., UMA, HND, and KSM, were equipped with broadband seismometers $(30 \mathrm{~s}-50 \mathrm{~Hz})$. Low-frequency microphones were used at the infrasound stations (ACM, KWM, UMA, and HND; 0.1-1000 Hz). Seismic and infrasound signals are recorded at a sampling rate of $100 \mathrm{~Hz}$ at all stations. Among these stations, we focus mainly on the data from three stations, KAF, ACM, and UMA (Fig. 1c),

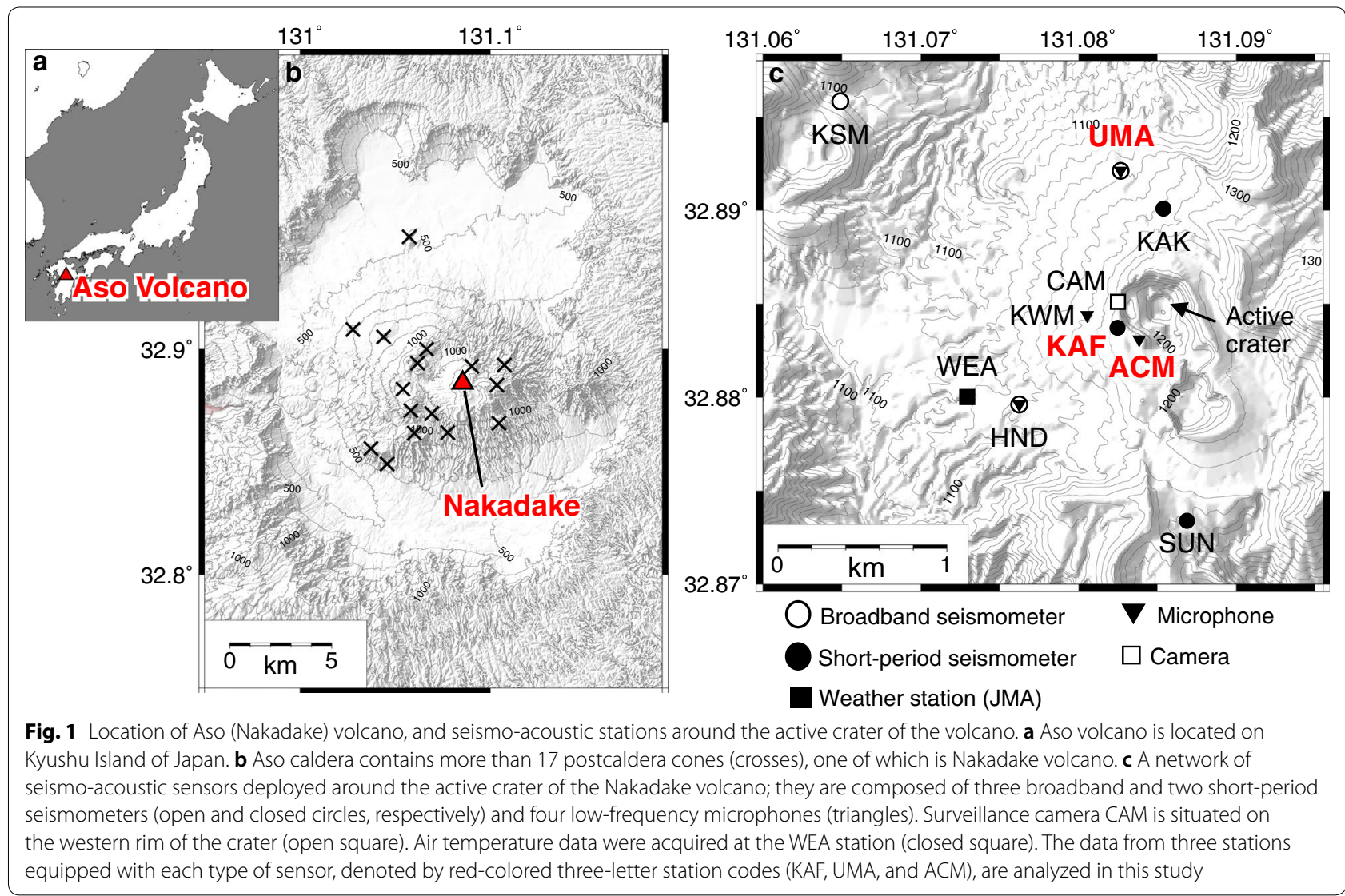




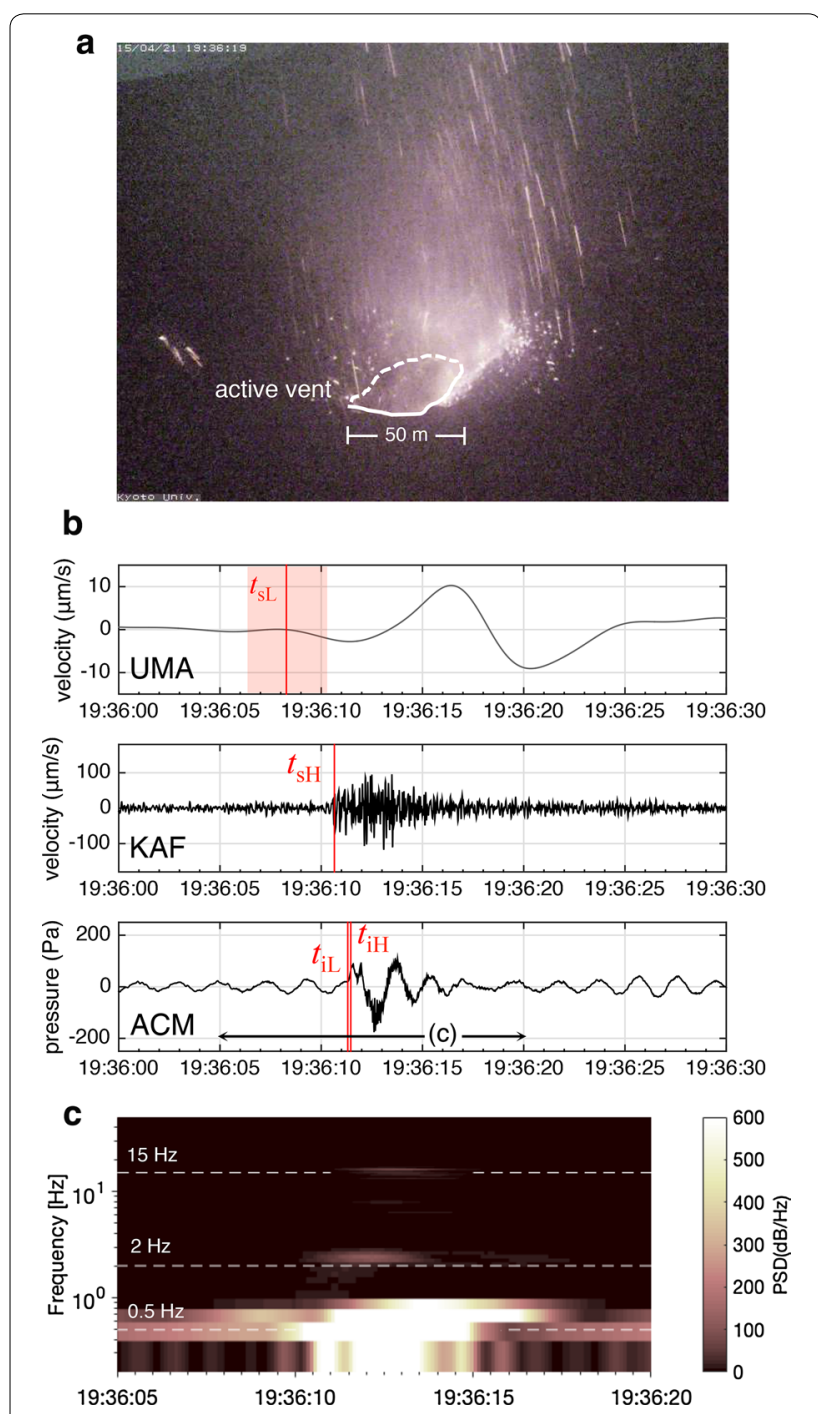

Fig. 2 Snapshot of a Strombolian explosion at Aso volcano and corresponding seismo-acoustic waveforms. a Ash-free Strombolian explosions (such as type 1 explosions; Patrick et al. 2007; Gaudin et al. 2017) captured by the CAM surveillance camera at 19:36 on 21 April 2015. Incandescent lapilli were ejected from the active vent at the crater center. $\mathbf{b}$ Seismo-acoustic waveforms of a Strombolian explosion on 21 April 2015 recorded at UMA, KAF and ACM stations. From bottom to top, the waveforms are the very-long-period (VLP) seismic signal $(<0.1 \mathrm{~Hz})$, eruption earthquake signal, and infrasound signal. Seismic signals at UMA and KAF are the vertical component. The VLP signal typically started with a downward motion at $t_{\text {sL }}$ (the pink-colored zone shows the reading error). The eruption earthquake signal emerged with a high-frequency and high-amplitude phase at $t_{\mathrm{sH}}$. The infrasound signal was composed of low- and high-frequency signals arrived at $t_{\mathrm{iL}}$ and $t_{\mathrm{iH}}$. $\mathbf{c}$ Power spectrogram of the infrasound signal computed for a 5 -s-long sliding window with a 0.1 -s overlap

which are the stations closest to the crater among each of the three types of sensors. A surveillance camera (sampling every $20 \mathrm{~s}$ ) was also installed on the crater rim of the west side (CAM) to monitor the eruption activity. A weather station (WEA) operated by the Japan Meteorological Agency recorded the air temperature.

We selected seismo-acoustic signals clearly associated with Strombolian explosions from our dataset. First, we identified explicit scenes with ash-free Strombolian explosions, such as type 1 explosions (Patrick et al. 2007; Gaudin et al. 2017), in the CAM images from 10 days in late April 2015 when many Strombolian explosions were observed (Fig. 2a). To search for the explosion scenes, we used 4-h images from each day around the times of sunrise and sunset. The images at those times were suitable for checking phenomena at the vent because they were dark enough to recognize incandescent particles but light enough to confirm gas or ash emissions. As a result, a total of $9 \mathrm{~h}$ of data were selected (Table 1). Then, to extract waveform data for each eruption event, we applied the STA/LTA method (Allen 1978) to the infrasound data of the ACM station using short and long time windows of $1 \mathrm{~s}$ and $40 \mathrm{~s}$, respectively. A threshold value of 2 lasting $>1.25 \mathrm{~s}$ was used to identify events. Consequently, 318 events $(>10 \mathrm{~Pa})$ were identified during the selected $9 \mathrm{~h}$ in late April.

Each ash-free Strombolian explosion at the Aso volcano was accompanied by characteristic seismo-acoustic signals (Fig. 2b). These signals were detected as a distinct VLP signal at UMA, an eruption earthquake signal at $\mathrm{KAF}$, and an eruption-related infrasound signal at ACM.

The VLP signal precedes both the high-frequency eruption earthquake and infrasound signals by $>3 \mathrm{~s}$ (top panel in Fig. 2b). The vertical seismogram of the VLP signal observed at UMA starts with a downward motion. This pattern is similar to the typical VLP signals observed during the calm period with the crater lake at Aso volcano in 1994-2010 (e.g., Figure 4 of Kawakatsu et al. (2000)). The frequency components of the VLP signals during the Strombolian explosions, including the peak at $12 \mathrm{~s}$ and some overtones, are also similar to those documented in previous studies (15 s and overtones; Kaneshima et al. 1996).

The eruption earthquakes following the VLP signals (middle panel in Fig. 2b) were occasionally marked by an initial phase with low-frequency $(4-10 \mathrm{~Hz}$; Zobin and Sudo 2017) and low-amplitude characteristics. However, in an overwhelming majority of our datasets, this phase was not as evident as in the early stage of the 2014-2015 eruption (Zobin and Sudo 2017). On the other hand, the main phase, characterized by high-frequency and highamplitude signals, was highly evident (10-13 Hz; Fig. 2b). Assuming that the source location was the position of the active vent at the crater surface, the apparent horizontal propagation velocity of the eruption earthquake signal was approximately $2.65 \mathrm{~km} / \mathrm{s}$ based on all the seismic stations' data. This result is roughly consistent with the 
Table 1 Number of selected Strombolian explosion events

\begin{tabular}{lll}
\hline Date and time (local time) & $\begin{array}{l}\text { Number } \\
\text { of events }\end{array}$ \\
\hline 18 April 2015 & $19: 00-20: 00$ & 33 \\
19 April & 05:00-07:00 & 71 \\
21 April & $05: 00-07: 00$ & 88 \\
& $18: 00-20: 00$ & 82 \\
25 April & $18: 00-20: 00$ & 44 \\
\hline
\end{tabular}

P-wave velocity of $2.7 \mathrm{~km} / \mathrm{s}$ in a shallow region of the crater area of this volcano (Tsutsui et al. 2003).

As shown in the bottom panel in Fig. 2b, the infrasound signal associated with the Strombolian explosions was typically characterized by a higher-frequency component $(12-16 \mathrm{~Hz})$ overlapping a low-frequency oscillating wave $(0.5 \mathrm{~Hz}$ and $2 \mathrm{~Hz})$ with a time delay (Fig. 2c). The $0.5 \mathrm{~Hz}$ oscillations comprising the basic shape of the waveform lasted 5-10 s or longer. Signals in the same frequency band were also observed continuously during the entire period of the 2014-2015 eruption, regardless of the surficial phenomenon at the vent, such as ash venting, Strombolian explosion, steam or gas emission, or no activity (Yokoo et al. 2019). This signal might be related to the resonant tone of the space in the conduit above the magma surface and may be triggered by an incident signal such as an explosion (Yokoo et al. 2019). The $2 \mathrm{~Hz}$ wave appeared to emerge at almost the same time as the $0.5 \mathrm{~Hz}$ amplification. The higher-frequency (12$16 \mathrm{~Hz}$ ) component appeared $\sim 0.3 \mathrm{~s}$ after the start of the low-frequency components and lasted $\sim 5 \mathrm{~s}$. The delay of the high-frequency component following the first low-frequency wave is also generally observed at Stromboli volcano (e.g., Vergniolle and Brandeis 1994).

\section{Time differences of signals}

We determined the arrival times of each onset of the VLP signal at UMA, the eruption earthquake at KAF, and the low- and high-frequency components of the infrasound signals at ACM for all 318 events $\left(t_{\mathrm{sL}}, t_{\mathrm{sH}}, t_{\mathrm{iL}}\right.$, and $t_{\mathrm{iH}}$, respectively) (Fig. 2b). For these parameters, the lowercase first subscript letter ( $\mathrm{s}$ and i) indicates a seismic or infrasound signal, and the capital second letter ( $\mathrm{L}$ and $\mathrm{H}$ ) indicates a low- or high-frequency component. It is difficult to identify the accurate arrival time of the VLP signal $\left(t_{\mathrm{sL}}\right)$ due to the more prolonged ( $\left.12 \mathrm{~s}\right)$ nature of the signal, as noted above. We excluded ambiguous events and assigned a reading error to $t_{\mathrm{sL}}$ of $\pm 2 \mathrm{~s}$. The onset of the eruption earthquake $\left(t_{\mathrm{sH}}\right)$ was considered the main phase by Zobin and Sudo (2017) and is characterized by a high frequency and a large amplitude. The $t_{\mathrm{iL}}$ and $t_{\mathrm{iH}}$ values of the infrasound wave were determined using $10-\mathrm{Hz}$ lowpassed and $10-\mathrm{Hz}$ high-passed waveforms of the ACM record. The reading uncertainties in $t_{\mathrm{sH}}, t_{\mathrm{iL}}$, and $t_{\mathrm{iH}}$ were less than $\pm 0.05 \mathrm{~s}$.

We obtained the time differences in arrival times between the VLP and infrasound low-frequency signals, $\Delta t_{\mathrm{SL}-\mathrm{iL}}$, as shown in Fig. 3a. The results did not show a normal distribution and were instead skewed, with a mean and mode of $3.84 \mathrm{~s}$ and $2.90 \mathrm{~s}$, respectively. The time differences between the eruption earthquake signals and the high-frequency infrasound signals, $\Delta t_{\mathrm{sH}-\mathrm{iH}}$, were distributed almost symmetrically about $1.00 \mathrm{~s}$ (Fig. 3b), with a mean and mode of $0.96 \mathrm{~s}$ and $1.15 \mathrm{~s}$, respectively. The time differences between infrasound low- and
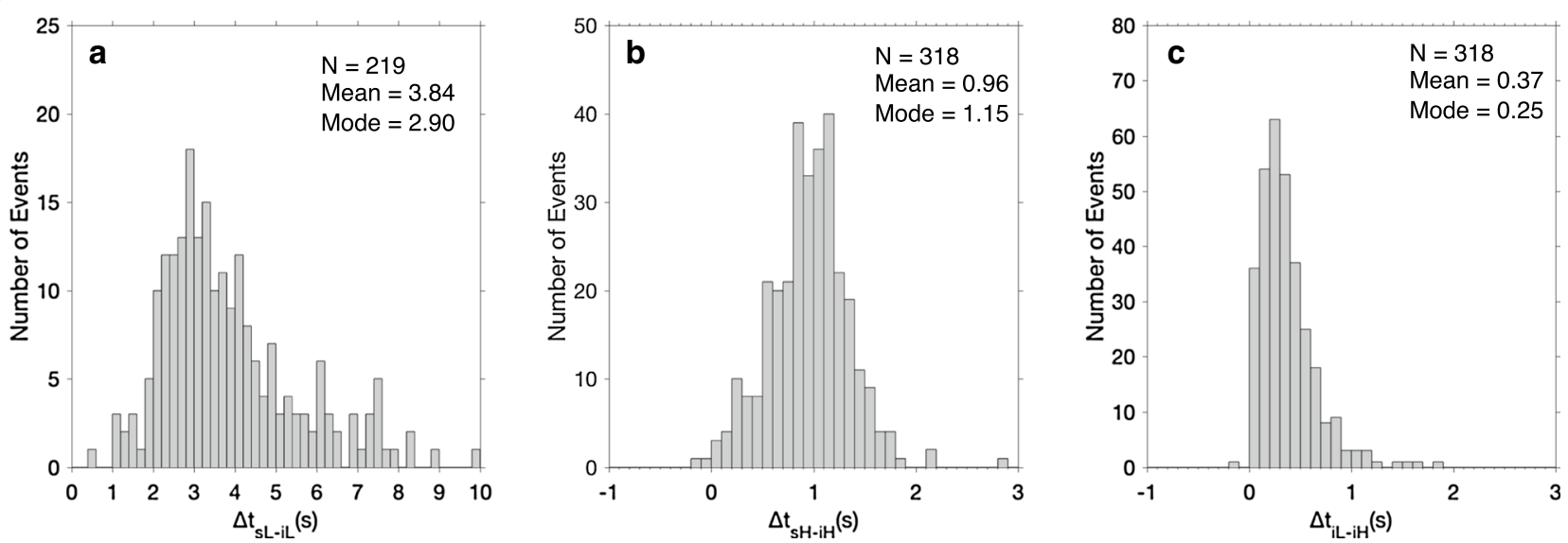

Fig. 3 Histograms of observed differences in seismo-acoustic signal arrival times. a Distribution of time differences between the arrival of the VLP seismic signal at UMA and the arrival of the low-frequency infrasound signal at $A C M, \triangle t_{\text {SL-iL }}$. $\mathbf{b}$ Distribution of time differences between the eruption earthquake at KAF and the high-frequency infrasound signal at $A C M, \Delta t_{\mathrm{SH}-\mathrm{iH}}$. $\mathbf{C}$ Distribution of time differences between low-and high-frequency infrasound signals at $A C M, \Delta t_{\mathrm{iL}-\mathrm{iH}}$. The total number of events $(\mathrm{N})$ and the mean and mode values are shown in the upper right in each diagram 
high-frequency signals, $\Delta t_{\mathrm{iL}-\mathrm{iH}}$, also presented a strongly skewed distribution (Fig. 3c), with a mean and mode of 0.37 and $0.25 \mathrm{~s}$, respectively. In this case, most events (97\%) featured values of less than $1.00 \mathrm{s.}$

\section{Discussion}

During the occurrence of ash-free Strombolian explosions at Aso volcano in April 2015, we identified characteristic seismo-acoustic signals, such as the VLP signal, eruption earthquake signal, and explosion infrasound signal (Fig. 2b). All these signals have also been commonly observed at other volcanoes with Strombolian explosions (e.g., Stromboli, Erebus, and Yasur volcanoes; Harris and Ripepe 2007; Rowe et al. 2000; Marchetti et al. 2013). Following Ripepe et al. (2001), we can constrain two essential parameters related to the dynamics of a Strombolian explosion - the explosion depth and the ascent velocity of the gas phase-using the time differences in the arrival times of these seismo-acoustic signals. The latter parameter is especially vital for investigating how the gas phase rises in the magma conduit, which could control the explosivity of the eruption.

As a basis for discussion, we assumed here a simple model of Strombolian explosion, as depicted in Fig. 4a$\mathrm{d}$, in which (a) a pressurized gas pocket first approaches the magma free surface in the conduit; (b) gas inside the bubble pushes the overlying magma up at the magma surface; (c) disruption of the magma film is followed by subsequent gas jetting from the gas pocket with magma fragments; and (d) the emission continues for several seconds. In stage $b$, low-frequency infrasound signals $(2 \mathrm{~Hz})$ are produced due to the swelling of the magma surface above the gas pocket (Delle Donne and Ripepe 2012; Goto et al. 2014) or oscillation of the liquid film of the gas pocket before it bursts (Vergniolle and Brandeis 1994, 1996). Both the eruption earthquake (the main phase in Zobin and Sudo 2017) and the high-frequency infrasound signals $(12-16 \mathrm{~Hz})$ can be simultaneously generated in the conduit by the processes in stages $\mathrm{c}$ and $\mathrm{d}$ (Braun and Ripepe 1993; Vergniolle and Brandeis 1994) because both signals we observed had a similar frequency of $10-15 \mathrm{~Hz}$ (Fig. 2b, c). At Stromboli volcano, during the continuous emission of both gas and magma fragments from the vent (Genco et al. 2014), the high-frequency infrasound signal followed the first appearance of the lower-frequency one. We consider that similar processes, a break in the magma film and the subsequent forcible ejection of depressurized gasses, occurred $\sim 0.3 \mathrm{~s}$ after the arrival of the gas pocket at the magma surface in the conduit.

\section{Explosion depth}

Based on the above assumptions about the seismoacoustic signals, we attempted to estimate the explosion depths by using the differences in arrival times between the eruption earthquake signals and the high-frequency infrasound signals. The eruption earthquake signal travels from a source inside the conduit to the station KAF with a velocity of $v_{\mathrm{sH}}$ (Fig. 4e). Hence, the travel time for the earthquake signal $\tau_{\mathrm{sH}}$ can be written as

$$
\tau_{s H}=\frac{L_{\mathrm{sH}}}{v_{\mathrm{sH}}}=\frac{\sqrt{\left(d_{\mathrm{exp}}+h_{\mathrm{sH}}\right)^{2}+l_{\mathrm{sH}}^{2}}}{v_{\mathrm{P}}} .
$$

The propagation path length for the eruption earthquake signal $L_{\mathrm{sH}}$ is geometrically defined using three variables: the depth of the magma free surface from the crater floor $\left(d_{\text {exp }}\right)$, the height of the KAF station from the crater floor $\left(h_{\mathrm{sH}} ; 130 \mathrm{~m}\right)$, and the horizontal distance from the vent to $\operatorname{KAF}\left(l_{\mathrm{sH}} ; 260 \mathrm{~m}\right)$. The velocity $v_{\mathrm{sH}}$ is assumed to be the P-wave velocity at Aso volcano $\left(v_{\mathrm{P}} ; 2.7 \mathrm{~km} / \mathrm{s}\right.$; Tsutsui et al. 2003). In contrast, the time for the infrasound signal to travel from the source to the ACM station $\tau_{\mathrm{iH}}$ is expressed using the total path length and propagation velocity, $L_{\mathrm{i}}$ and $\bar{v}_{\mathrm{i}}$, respectively. This relationship can be written as

$$
\tau_{\mathrm{iH}}=\frac{L_{\mathrm{i}}}{\bar{v}_{\mathrm{i}}}=\frac{d_{\mathrm{exp}}}{c_{\mathrm{con}}}+\frac{L_{\mathrm{i}}^{\prime}}{c_{\mathrm{air}}},
$$

where $c_{\text {con }}$ is the sound velocity inside the conduit above the magma surface, $L_{i}^{\prime}$ is the propagation path length from the vent to the station ACM $(290 \mathrm{~m})$, and $c_{\text {air }}$ is the sound velocity in air. The sound velocity in air is estimated to be $337.8 \mathrm{~m} / \mathrm{s}$ at the average air temperature $\left(10.5{ }^{\circ} \mathrm{C}\right)$ measured at WEA station in April 2015 (refer to Additional file 2). Therefore, the arrival time difference between the eruption earthquake signal and the infrasound signal can be expressed as

$$
\begin{aligned}
\Delta t_{\mathrm{sH}-\mathrm{iH}} & =\tau_{\mathrm{iH}}-\tau_{\mathrm{sH}}=\left(\frac{d_{\exp }}{c_{\mathrm{con}}}+\frac{L_{\mathrm{i}}^{\prime}}{c_{\mathrm{air}}}\right) \\
& -\frac{\sqrt{\left(d_{\exp }+h_{\mathrm{sH}}\right)^{2}+l_{\mathrm{sH}}^{2}}}{v_{\mathrm{P}}} .
\end{aligned}
$$

In a Strombolian explosion, the space in the conduit above the magma free surface is occupied by a mixture of volcanic gas and magma fragments (Fig. 2a). The sound velocity in this space $c_{\text {con }}$ is a variable that fluctuates greatly with the inner conduit conditions and is affected by a combination of the chemical composition of the gas, the gas mass fraction of ash, and the gas temperature (e.g., Morrissey and Chouet 2001; refer to Additional file 2). The gas composition during the 2014-2015 eruption was characterized by $\mathrm{H}_{2} \mathrm{O}: \mathrm{CO}_{2}: \mathrm{SO}_{2}$ proportions of 90:4:4 (Shinohara et al. 2018). The gas mass fraction 

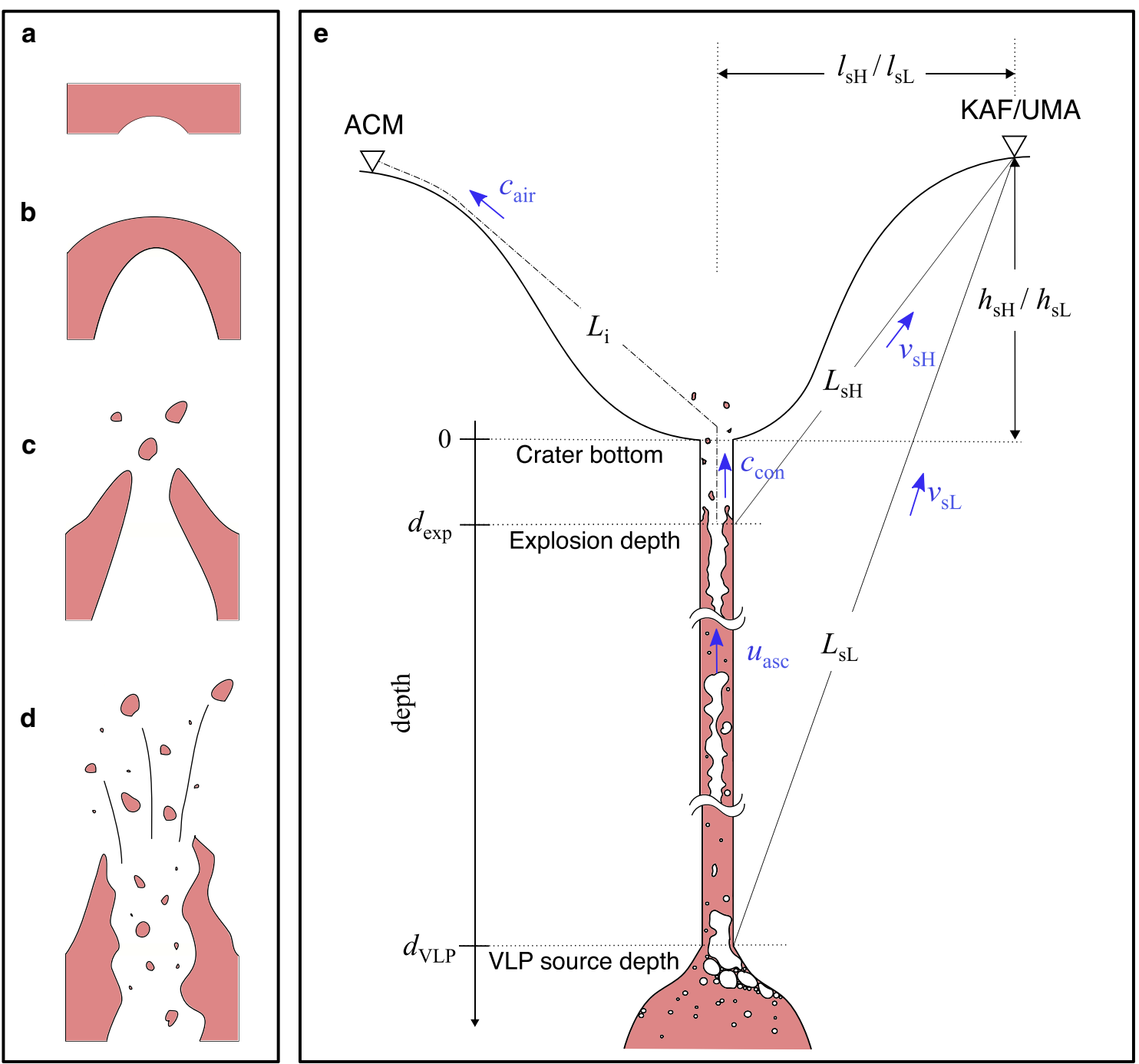

Fig. 4 A conceptual model of Strombolian explosion processes. $\mathbf{a}$ and $\mathbf{b}$ Just before an explosion, the magma surface swells due to the arrival of a gas pocket, generating the low-frequency $(2 \mathrm{~Hz})$ infrasound signal. $\mathbf{c}$ In the next moment, the magma film at the surface is ruptured, and gas and magma fragments start to be ejected. High-frequency seismic and infrasound signals are generated at this time. $\mathbf{d}$ Afterward, ejection of the gas and magma fragments continues for several seconds. e Model parameterization geometry for a Strombolian explosion and its seismo-acoustic signals propagating to the stations. The gas phase rises with a velocity of $u_{\text {asc }}$ in the conduit from a depth of $d_{\text {VLP }}$ where the VLP signal is produced. When the gas phase (gas pocket) reaches the magma surface at a depth of $d_{\text {exp }}$ low-frequency infrasound is produced. Soon afterward, a Strombolian explosion occurs, generating both an eruption earthquake and high-frequency infrasound signals. The VLP and eruption earthquake signals propagate through the ground with velocities of $v_{\mathrm{SL}}$ and $v_{\mathrm{SH} \text {, }}$ respectively. In contrast, low- and high-frequency infrasound signals propagate through the air with sound velocities of $c_{\text {con }}$ in the conduit and $c_{\text {air }}$ above the crater floor

during an ash-free Strombolian explosion typically ranges from 0.65 to 0.95 (Patrick 2007). The gas temperature is assumed to be 400-1300 $\mathrm{K}$ according to both our observed values at the active vent $\left(60-100{ }^{\circ} \mathrm{C}\right.$ in temperature images using an infrared thermal camera; FLIR T440) and magma temperature inferred from a petrological analysis $\left(1100{ }^{\circ} \mathrm{C}\right.$; National Institute of Advanced Industrial Science and Technology 2015). According to these parameters, $c_{\text {con }}$ could range from 320 to $700 \mathrm{~m} / \mathrm{s}$ (Fig. 5a). In the calculation, the molar specific heats of the relevant gasses $\left(\mathrm{CO}_{2}, \mathrm{SO}_{2}\right.$, and $\left.\mathrm{H}_{2} \mathrm{O}\right)$ with respect to temperature at constant pressure were referenced from the Japan Society of Mechanical Engineers (1986) and Wagner and Pruß (2002). Both the molar specific heat of the solids (ash particles) at a constant pressure and that at a constant volume are $954 \mathrm{~J} \mathrm{~K}^{-1} \mathrm{~mol}^{-1}$ (Morrissey and Chouet 2001).

By substituting all parameters mentioned above into Eq. $3, d_{\exp }$ is a function of only two variables: $\Delta t_{\mathrm{sH}-\mathrm{iH}}$ and $c_{\text {con }}$. Therefore, we can obtain the distribution of 

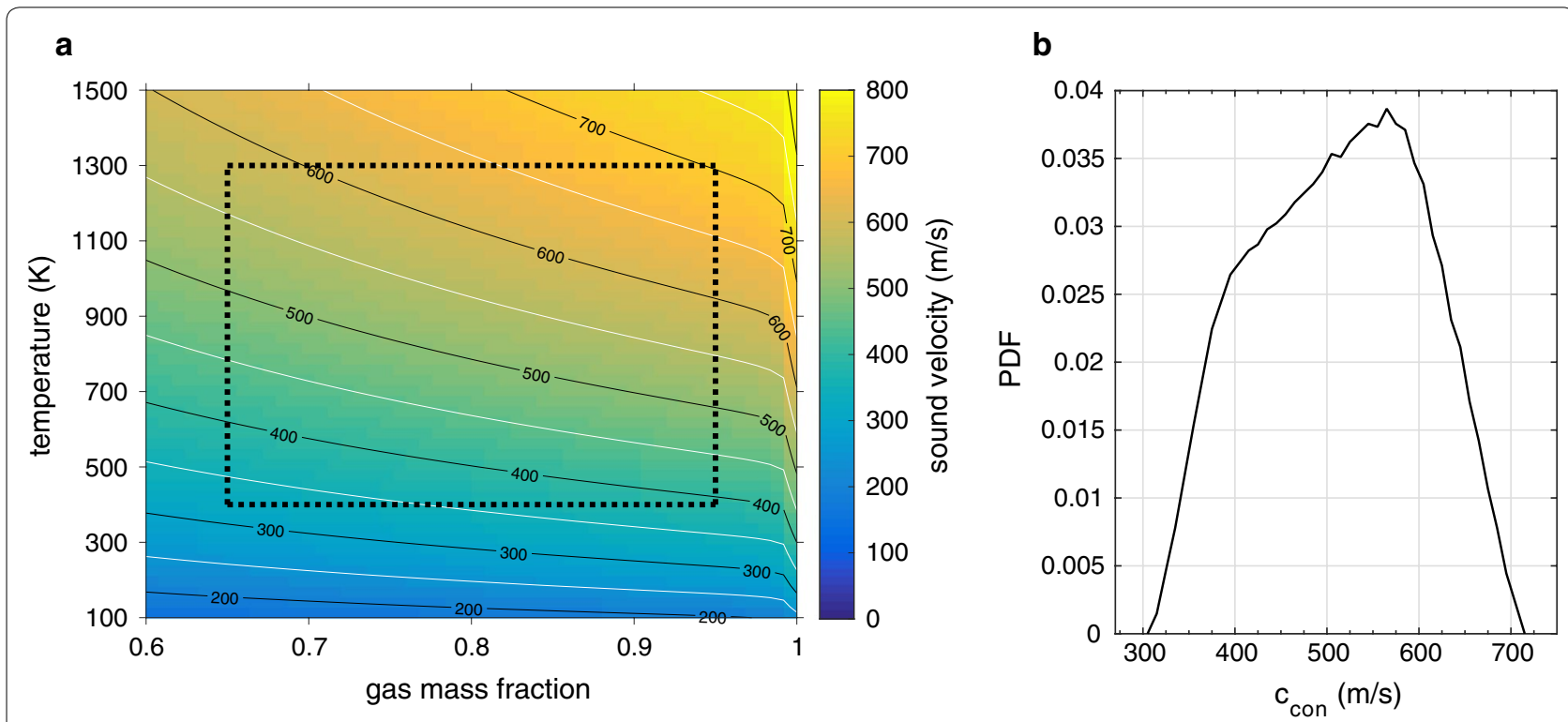

Fig. 5 Estimated sound velocity inside the conduit above the magma surface. a Sound velocity inside the conduit above the magma surface depends both on the air temperature and the gas mass fraction (Morrissey and Chouet 2001). In this study, we considered these values to be 400-1300 K and 0.65-0.95, respectively, resulting in a range of 320-700 m/s (area within the black dashed line). b Probability density function of estimated sound velocity for a temperature range and gas mass fraction range of 400-1300 K and 0.65-0.95, respectively

$d_{\text {exp }}$ from the distribution of $\Delta t_{\mathrm{sH}-\mathrm{iH}}$ (Fig. 3b) when $c_{\text {con }}$ is fixed. To estimate the $d_{\text {exp }}$ of the Strombolian explosions at Aso volcano, we multiply the probability density function (PDF) of $\Delta t_{\mathrm{sH}-\mathrm{iH}}$ by the PDF of $c_{\mathrm{con}}$ with a range of $320-700 \mathrm{~m} / \mathrm{s}$ (Fig. $5 \mathrm{~b}$ ). As a result, the PDF of $d_{\exp }$ was estimated, as shown in Fig. 6, in which it is plotted against the range of $c_{\text {con }}$. The depths at which the explosion events occurred with a probability of more than $50 \%$ (interior of the black contour in Fig. 6) were $<400 \mathrm{~m}$. This result was independent of variations in $c_{\text {con }}$. This depth is consistent with a shallow region in the fluid transport system in Aso volcano (Ichimura et al. 2018), which includes the upper portion of a sizable crack-shaped conduit ( $300 \mathrm{~m}$ depth; Yamamoto et al. 1999). The crack beneath the crater is thought to be the source location of the VLP events (Yamamoto et al. 1999; Kawakatsu et al. 2000). The result indicating that the explosion sources are located above the depth of the VLP sources suggests that the occurrence of a VLP event triggers the subsequent Strombolian explosion in the shallow region.

\section{Ascent velocity}

The VLP events at Stromboli volcano are thought to be generated when a slug migrates through a crack located beneath the active vent (Chouet et al. 2003). At Aso volcano, the existence of a large crack beneath the chain of

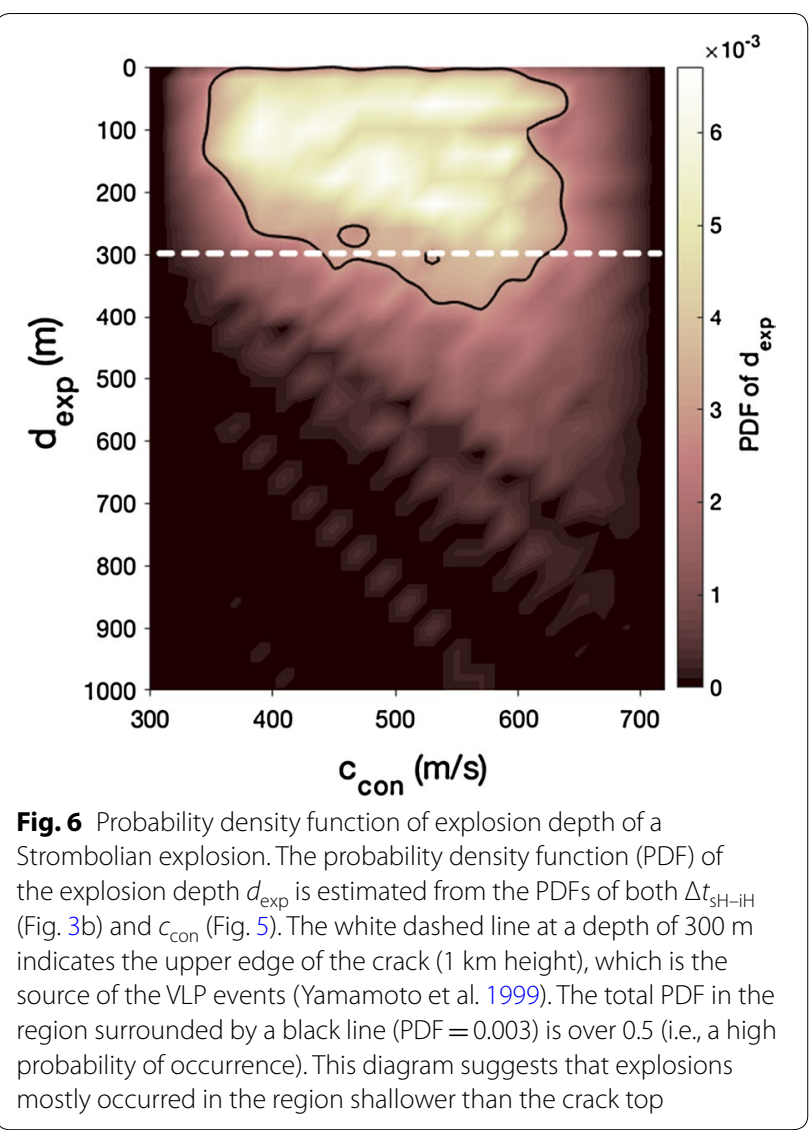


craters during the noneruptive period (1994-2010) has also been proposed based on a moment tensor analysis of the VLP signals (Yamamoto et al. 1999). These signals were attributed to the resonance of volcanic gas in the crack triggered by flow instability. The instability started in the upper portion of the crack, where the crack narrowed into a cylindrical conduit approaching the crater bottom (Yamamoto 2005). The features of the VLP signals observed during the period of Strombolian explosions at Aso volcano in 2014-2015 are quite similar to those observed during the noneruptive period (Fig. 2b). This similarity suggests that the signals in both the noneruptive and eruptive periods are generated by a similar mechanism. Therefore, we assumed that the generation of the VLP signals is related to the insertion of a gas cluster from the upper portion of the crack into the overlying cylindrical conduit by foam collapse (Jaupart and Vergniolle 1989). This process can effectively produce pressure disturbances inside the crack and induce the VLP signal we observed.

Based on our assumption of the VLP event's excitation process described above (Fig. 4e), we can calculate the ascent velocity of the gas phase using a method similar to that used to estimate the explosion depth (Fig. 6). If the VLP source depth $d_{\mathrm{VLP}}(\mathrm{m})$ is considered to be the depth from which a gas cluster starts to ascend to the active vent (top of the crack; Fig. 4e), the time delay between the VLP and infrasound signals at the stations, $\Delta t_{\mathrm{sL}-\mathrm{iL}}$, can be described as follows:

$$
\begin{aligned}
\Delta t_{\mathrm{sL}-\mathrm{iL}} & =\tau_{\mathrm{iL}}+\tau_{\mathrm{asc}}-\tau_{\mathrm{sL}}=\left(\frac{d_{\mathrm{exp}}}{c_{\mathrm{con}}}+\frac{L_{\mathrm{i}}^{\prime}}{c_{\mathrm{air}}}\right) \\
& +\frac{d_{\mathrm{VLP}}-d_{\mathrm{exp}}}{u_{\mathrm{asc}}}-\frac{\sqrt{\left(d_{\mathrm{VLP}}+h_{\mathrm{sL}}\right)^{2}+l_{\mathrm{sL}}^{2}}}{v_{\mathrm{sL}}},
\end{aligned}
$$

where $\tau_{\mathrm{iL}}, \tau_{\mathrm{asc}}$, and $\tau_{\mathrm{sL}}$ are the travel time of the low-frequency infrasound signal from the explosion depth to the infrasound station ACM, the ascent time of the gas phase in the conduit from the VLP source (top of the crack) to the explosion depth, and the travel time of the VLP signal from the source to the station UMA, respectively. $\tau_{\mathrm{iL}}$ (the first term in Eq. 4) is the same as $\tau_{\mathrm{iH}}$ (Eq. 2), and $\tau_{\mathrm{sL}}$ (the third term) is defined similarly to $\tau_{\mathrm{sH}}$ (Eq. 1) with four variables: the depth of the upper end of the crack $d_{\mathrm{VLP}}$, the height of the UMA station from the crater floor $\left(h_{\mathrm{sL}}\right.$; $45 \mathrm{~m})$, the horizontal distance from the vent to the UMA $\left(l_{\mathrm{sL}} ; 830 \mathrm{~m}\right)$, and the phase velocity of the VLP signal $\left(v_{\mathrm{sL}}\right)$. For $d_{\mathrm{VLP}}$, we consider three values, 300,400 , and $500 \mathrm{~m}$, according to the size of the crack estimated by Yamamoto et al. (1999). We set the minimum depth at $300 \mathrm{~m}$ because the relationship, $d_{\exp }<d_{\mathrm{VLP}}$, should be maintained as long as the discussion is based on the assumption of the CF model (Fig. 6). Considering a near-field effect, $v_{\mathrm{sL}}$ should be a value between the P-wave velocity $(2700 \mathrm{~m} / \mathrm{s})$ and the S-wave velocity $(1585 \mathrm{~m} / \mathrm{s}$; Sudo and Kong 2001); thus, both velocities are used for our calculation. The second term (travel time $\tau_{\text {asc }}$ ) is regarded as the time required for a gas phase to ascend from $d_{\mathrm{VLP}}$ to $d_{\text {exp }}$ at the velocity of $u_{\text {asc }}$.

Equation 4 can be rewritten into a much simpler form because it is a function of the three variables $d_{\exp }, c_{\text {con }}$, and $u_{\text {asc }}$ :

$$
\Delta t_{\mathrm{sL}-\mathrm{iL}}=\mathcal{F}\left(d_{\text {exp }}, c_{\text {con }}, u_{\text {asc }}\right) .
$$

Therefore, we can obtain the ascent velocity of the gas phase as follows:

$$
u_{\text {asc }}=\mathcal{F}^{-1}\left(d_{\text {exp }}, c_{\text {con }}, \Delta t_{\text {sL-iL }}\right) .
$$

Note that $d_{\exp }$ is a function of two parameters: $\Delta t_{\mathrm{sH}-\mathrm{iH}}$ and $c_{\text {con }}$ (Eq. 3). Moreover, $\Delta t_{\mathrm{sL}-\mathrm{iL}}$ and $\Delta t_{\mathrm{sH}-\mathrm{iH}}$ correspond one-to-one for each explosion event. These two facts can be used to write a new relation:

$$
u_{\mathrm{asc}}=\mathcal{G}\left(c_{\mathrm{con}}, d t\left(\Delta t_{\mathrm{sL}-\mathrm{iL}}, \Delta t_{\mathrm{sH}-\mathrm{iH}}\right)\right) \text {, }
$$

using a new concept of $d t$, which is determined by a combination of $\Delta t_{\mathrm{sL}-\mathrm{iL}}$ and $\Delta t_{\mathrm{sH}-\mathrm{iH}}$.

From this relationship, we consequently obtained the PDF of $u_{\text {asc }}$ by multiplying the PDFs of $c_{\text {con }}$ and $d t$, as shown in Fig. 7. This figure includes six diagrams with different parameters of $d_{\mathrm{VLP}}(300,400$, and $500 \mathrm{~m})$ and $v_{\mathrm{SL}}\left(v_{\mathrm{P}}\right.$ and $\left.v_{\mathrm{S}}\right)$. The area surrounded by the black contour line indicates more probable explosion events $(>50 \%$ in total), similar to Fig. 6. A difference in $v_{\mathrm{sL}}$ does not affect the estimated range of the $u_{\text {asc }}$ values (in the same row in Fig. 7; for example, at $d_{\mathrm{VLP}}=300 \mathrm{~m}, u_{\mathrm{asc}}=3-86 \mathrm{~m} / \mathrm{s}$ and $2-79 \mathrm{~m} / \mathrm{s}$ for $v_{\mathrm{sL}}=2700 \mathrm{~m} / \mathrm{s}$ and $1585 \mathrm{~m} / \mathrm{s}$, respectively (Sudo and Kong 2001); at $d_{\mathrm{VLP}}=500 \mathrm{~m}, u_{\mathrm{asc}}=37-160 \mathrm{~m} / \mathrm{s}$ and $39-151 \mathrm{~m} / \mathrm{s}$ ). In contrast, differences in $d_{\mathrm{VLP}}$ have an effect on $u_{\text {asc }}$ (in the column in Fig. 7). Deepening of the crack depth causes an increase in the gas ascent velocity, and $d_{\mathrm{VLP}} \mathrm{s}$ values of 300,400 , and $500 \mathrm{~m}$ correspond to $u_{\text {asc }}$ values of $2-86 \mathrm{~m} / \mathrm{s}, 1-130 \mathrm{~m} / \mathrm{s}$, and $37-160 \mathrm{~m} / \mathrm{s}$, respectively. Thus, we conclude that the ascent velocities of the gas phase in the conduit are in the range of $1-160 \mathrm{~m} / \mathrm{s}$ based on our calculations.

\section{Gas flow dynamics in the conduit}

During Strombolian explosions at Aso volcano, the ascent velocities of the gas phase estimated from the differences in arrival times of seismo-acoustic signals (VLP, eruption earthquake and infrasound signals) were in the range of $1-160 \mathrm{~m} / \mathrm{s}$ (Fig. 7). This range encompasses the estimated velocity ranges for cases at Stromboli volcano $(10-70 \mathrm{~m} / \mathrm{s}$ and $13-25 \mathrm{~m} / \mathrm{s}$; Harris and Ripepe 2007; Gurioli et al. 2014). The estimation methods of these two papers at Stromboli volcano were almost the same as our 

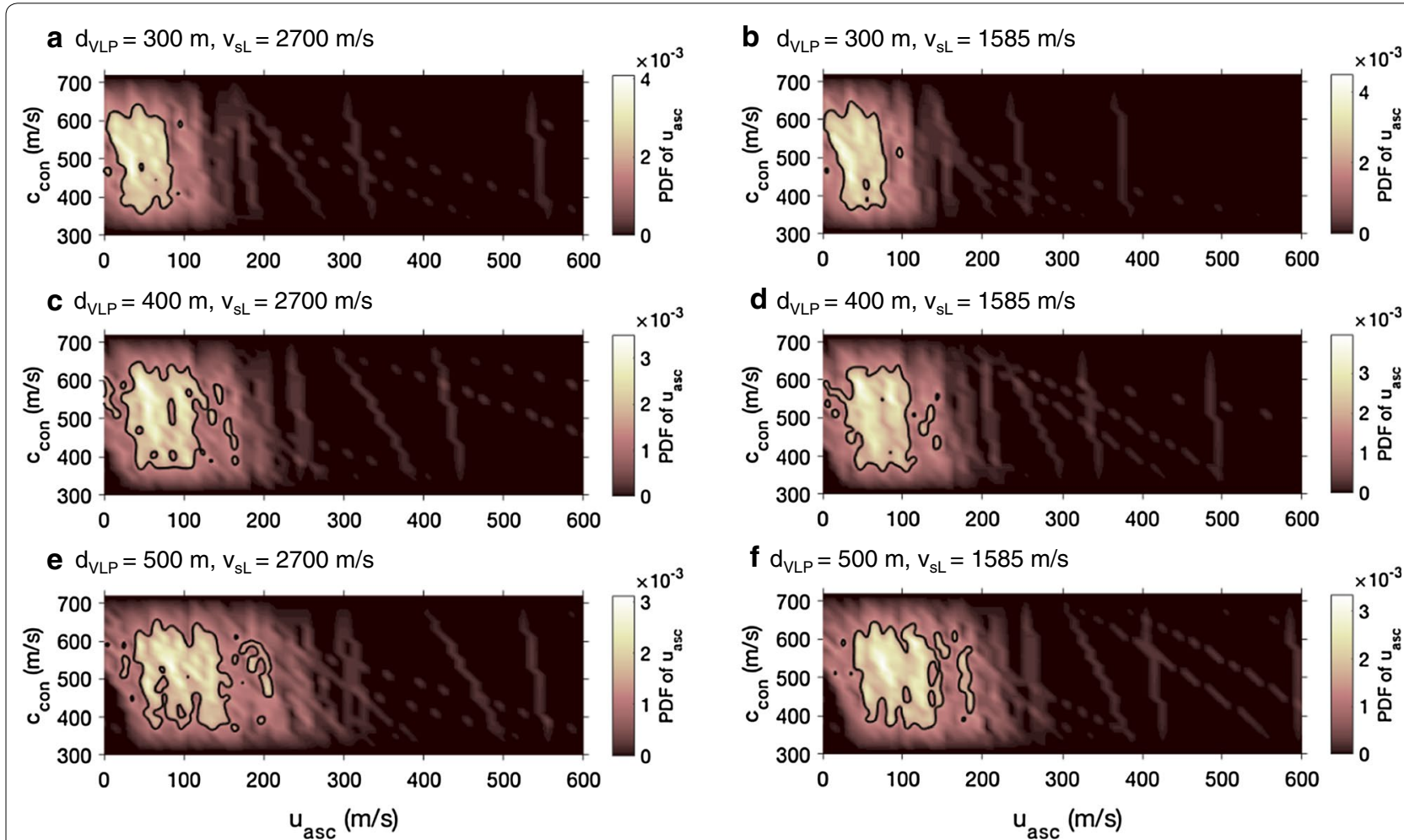

d $d_{V L P}=400 \mathrm{~m}, \mathrm{v}_{\mathrm{sL}}=1585 \mathrm{~m} / \mathrm{s}$

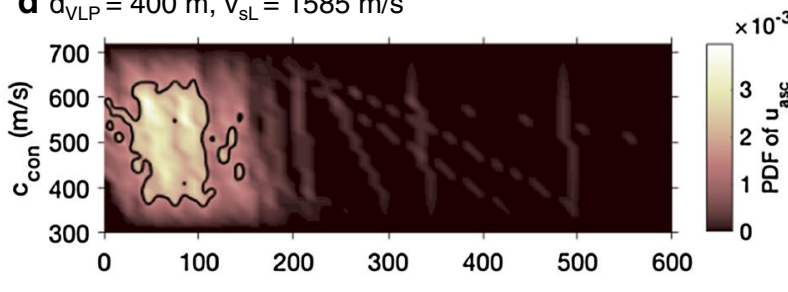

f $\mathrm{d}_{\mathrm{VLP}}=500 \mathrm{~m}, \mathrm{v}_{\mathrm{sL}}=1585 \mathrm{~m} / \mathrm{s}$

Fig. 7 Probability density function of ascent velocity of the gas phase in the conduit. Probability density function of the ascent velocity of the gas phase $\left(u_{\text {asc }}\right)$ with different conditions of the VLP source depth $\left[d_{V L P} ; 300 \mathrm{~m}(\mathbf{a}, \mathbf{b}), 400 \mathrm{~m}(\mathbf{c}, \mathbf{d})\right.$, and $\left.500 \mathrm{~m}(\mathbf{e}, \mathbf{f})\right]$ and the propagation velocity of the VLP signal $\left[V_{s L} ; 2700 \mathrm{~m} / \mathrm{s}(\mathbf{a}, \mathbf{c}, \mathbf{e})\right.$ and $\left.1585 \mathrm{~m} / \mathrm{s}(\mathbf{b}, \mathbf{d}, \mathbf{f})\right]$. The meaning of the black lines in all the diagrams is the same as in Fig. 6

estimation method and were also based on a similar simple model of the explosion, as shown in Figs. 4 and 9a: a gas pocket ascends in the conduit and then bursts at the magma surface.

From an investigation of the theoretical basis (Batchelor 1967; Viana et al. 2003), the ascent velocity of a slug $u_{\text {asc }}$ in a vertical pipe filled with a liquid is expressed by

$$
u_{\mathrm{asc}}=\operatorname{Fr} \sqrt{D g}
$$

in which $F r, D$, and $g$ are a dimensionless number (the Froude number), the diameter of the pipe, and gravitational acceleration, respectively. From compilations of large numbers of laboratory-scale experimental data by Viana et al. (2003), an empirical formula of the Froude number was defined using only dimensionless inverse viscosity $N_{\mathrm{f}}\left(N_{\mathrm{f}}=\rho_{\mathrm{l}} \sqrt{g D^{3}} / \mu\right.$, where $\rho_{\mathrm{l}}$ and $\mu$ are the density and viscosity of the liquid) when the Eötvös number $E o\left(=\rho_{\mathrm{l}} g D^{2} / \sigma\right.$, where $\sigma$ is the surface tension) is more than 40 (Llewellin et al. 2011):

$$
F r=0.34\left[1+\left(\frac{31.08}{N_{\mathrm{f}}}\right)^{1.45}\right]^{-0.71} .
$$

For the case of a gas slug in basaltic magma in a conduit, the range of Eo is $10^{5}<E o<10^{7}$ (Seyfried and Freundt 2000). For the case of the basaltic andesite magma at Aso, Eo is on the order of $\sim 10^{8}$. Both situations are satisfied with the condition of $E o>40$. Considering that $N_{\mathrm{f}}$ at Aso is $3.01 \times 10^{3}$ when $\rho_{\mathrm{l}}=2720 \mathrm{~kg} / \mathrm{m}^{3}$ (Namiki et al. 2018), $D=50 \mathrm{~m}$ (the maximum size; Fig. 2a) and $\mu=10^{3} \mathrm{~Pa} \mathrm{~s}$ (Giordano et al. 2008), the Froude number is 0.3397. From Eq. 9, the Froude number has never reached values greater than 0.34 regardless of the value of $N_{\mathrm{f}}$. This finding suggests that the ascent velocity of a gas slug, if present, in Aso volcano is estimated to be only $<7.5 \mathrm{~m} / \mathrm{s}$, assuming that the diameter of the conduit is $<50 \mathrm{~m}$ (Fig. 2a). This velocity is too low to explain the entire range of our estimated velocity results $(1-160 \mathrm{~m} / \mathrm{s}$; Fig. 7). The same inconsistency in velocities between values estimated from geophysical observation data (10$70 \mathrm{~m} / \mathrm{s}$ and 13-25 m/s; Harris and Ripepe 2007; Gurioli et al. 2014) and those predicted by an empirical relation $(0.11-2.6 \mathrm{~m} / \mathrm{s}$ and $1.5-3.4 \mathrm{~m} / \mathrm{s}$; Del Bello et al. 2012; Harris and Ripepe 2007) was previously reported at Stromboli volcano. 
This disagreement between observation-based and experiment-based ascent velocities suggests that the model of a gas slug ascending in the conduit does not adequately represent the Strombolian explosion process in the frame of the CF model. Here, we take into consideration other flow dynamics in the conduit to explain the fast ascent velocities estimated at Aso volcano. The flow regimes representing the gas ascent process in the low-viscosity magmatic system other than a slug ascent (slug flow) include churn flow and annular flow. Both of these regimes are types of continuous flow characterized by a higher superficial gas velocity $U_{\mathrm{sg}}$. The superficial gas velocity $U_{\mathrm{sg}}$ is defined as the volume flux of the gas divided by the cross-sectional area of the conduit $\left(\pi D^{2} / 4\right)$ (Taitel et al. 1980). As the superficial gas velocity increases in the liquid, the gas flow regime changes from slug flow to churn flow (e.g., Pioli et al. 2012). Churn flow is an unsteady flow because gas flux is sufficient to allow a part of the liquid film locally to lift upward (Hewitt 2012). With further increases in the gas flux, the flow regime changes to annular flow, which is characterized by both the existence of a central gas core and upward movement of the liquid film along the pipe wall (Taitel et al. 1980). These churn and annular flow models are usually adopted as interpretations of the lava fountain (Hawaiian) mechanism (Jaupart and Vergniolle 1988; Ulivieri et al. 2013).

We have found that our velocity estimation of $u_{\mathrm{asc}}$ is explained by the average gas velocity $U_{\mathrm{g}}$ of the annular flow regime. We calculated the average gas velocity $U_{\mathrm{g}}$ at the threshold between churn and annular flows because there are some expressions of this threshold that have been applied under the conditions in a conduit. The definition of $U_{\mathrm{g}}$ is the ratio of $U_{\mathrm{sg}}$ to the gas volume fraction (void ratio $\varepsilon$ ): $U_{\mathrm{g}}=U_{\mathrm{sg}} / \varepsilon$. Pushkina and Sorokin (1969) introduced the $U_{\mathrm{sg}}$ conditions corresponding to the transition from churn flow to annular flow as

$$
U_{\mathrm{sg}}=3.2\left[\frac{g \sigma\left(\rho_{\mathrm{l}}-\rho_{\mathrm{g}}\right)}{\rho_{\mathrm{g}}^{2}}\right]^{\frac{1}{4}},
$$

where $\sigma, \rho_{\mathrm{l}}$, and $\rho_{\mathrm{g}}$ represent the surface tension of magma $(\sim 0.1 \mathrm{~N} / \mathrm{m}$; Walker and Mullins 1981), the magma density $\left(2720 \mathrm{~kg} / \mathrm{m}^{3}\right.$; Namiki et al. 2018), and the gas density $\left(0.17-14 \mathrm{~kg} / \mathrm{m}^{3} ; \mathrm{H}_{2} 0\right.$ at $1300 \mathrm{~K}$ from $1 \mathrm{~atm}$ to $8 \mathrm{MPa}$ ), respectively. As shown in Eq. 10, $U_{\text {sg }}$ depends on the depth due to the variation in gas density. The gas volume fraction at the transition from churn to annular flows is estimated to be 0.45 (Pioli et al. 2012). Using the above conditions, we can predict $U_{\mathrm{g}}$ at each depth and the mean values $\left(\overline{U_{\mathrm{g}}}\right)$ of $U_{\mathrm{g}}$ between given depths and the surface (Fig. 8). For the range from 300 to $0 \mathrm{~m}, \overline{U_{\mathrm{g}}}$ is estimated to be $21 \mathrm{~m} / \mathrm{s}$. This velocity is relatively low with respect to the range of our $u_{\text {asc }}$ estimate $(1-160 \mathrm{~m} / \mathrm{s}$;

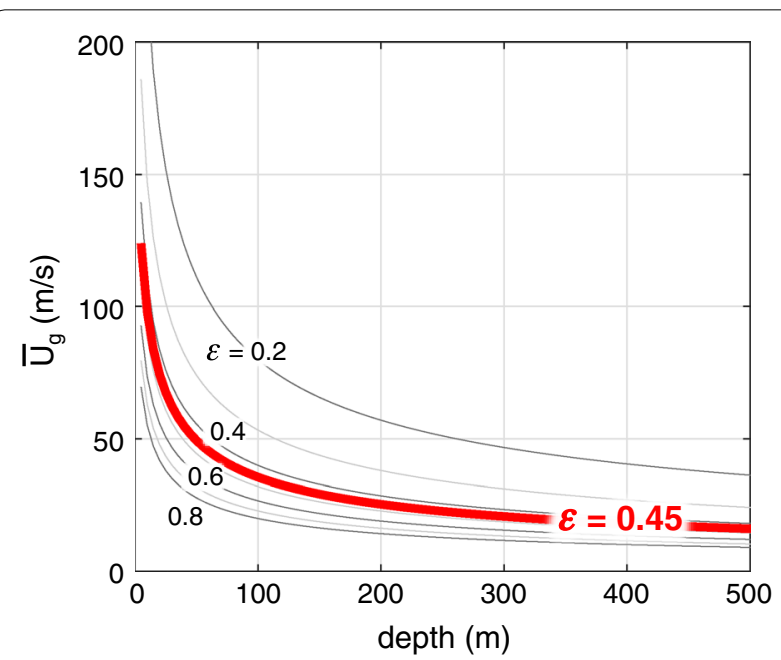

Fig. 8 Averaged gas velocity $\overline{U_{g}}$ from various depths to the surface. The horizontal axis shows the depth at which gas starts to rise, and the vertical axis shows the averaged velocity $\overline{U_{g}}$ when the gas rises from the depth to surface. The gas volume fraction is indicated by $\varepsilon$. We used $\varepsilon=0.45$ to estimate $\overline{U_{g}}$ (red line; Pioli et al. 2012)

Fig. 7). Therefore, most velocities of our $u_{\text {asc }}$ estimate are associated with annular flow.

We propose that during a Strombolian explosion in Aso volcano, the gas phase ascends via annular flow. Although annular flow is usually considered to be a form of continuous flow, we assume a transient flow with complicated dynamics. This flow is due to a temporary and sudden increase in the gas flux in the conduit caused by an injection of the gas phase at the base of the conduit. In our model (Fig. 9b left), tiny gas bubbles exsolved from the magma first accumulate in a narrow part of the crackshaped conduit. When the total concentration of bubbles exceeds the allowable (or threshold) value, the bubbles suddenly collapse, and the gas is injected into the conduit (Fig. 9b middle). This gas injection triggers the VLP earthquake. We infer that the gas injection volume rate is significant enough to make a gas channel to the magma surface akin to annular flow (Fig. 9b right). The ascending gas causes an explosion via the rupture of the magma film at the surface and subsequent gas emissions. In this process, the eruption earthquake and infrasound signals are generated, as described in Fig. 4a-d. The total volume of emitted gas is insufficient to maintain gas emissions for more than $\sim 10 \mathrm{~s}$. Then, these processes are repeated, producing a gas accumulation-injection (collapse) cycle.

Some observation data support our hypothesis. In a typical Strombolian explosion, a gas volume of $10-10^{4} \mathrm{~m}^{3}$ is emitted for $1-10 \mathrm{~s}$ (Del Bello et al. 2012). On the other hand, in the case of lava fountains, for example at Etna, a gas volume on the order of $10^{8} \mathrm{~m}^{3}$ can be emitted over $\sim 100 \mathrm{~min}$ (Ulivieri et al. 2013). 


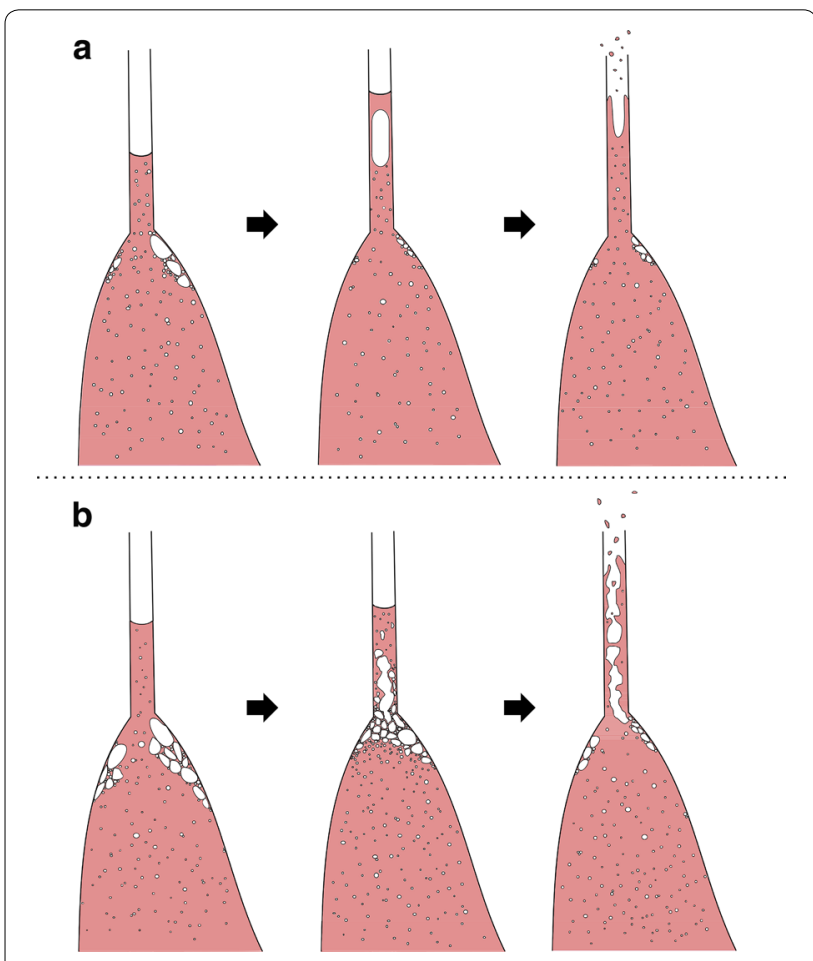

Fig. 9 Schematic models of a Strombolian explosion, a slug flow model and a new flow model. a A conceptual model based on the CF model of a Strombolian explosion that is widely accepted: bubbles accumulate at the roof of a magma chamber. They collapse into a slug and migrate upward in the conduit. An explosion occurs when the slug reaches the magma free surface. $\mathbf{b}$ New revised model of a Strombolian explosion we propose in this study: The accumulation of bubbles is the same; however, a relatively significant amount of the gas must be considered. The rapid injection of a large volume of gas produces a large upward gas flux, resulting in complicated dynamics, such as annular flow, in the conduit. The presence of a significant amount of gas can also form a temporary gas pathway connected to the surface. Magma films surrounding the pathway are so unstable during the rapid ascent of the gas that parts of them are fragmented and ejected

Based on these values, the gas volume flow rates are approximately $1-10^{4} \mathrm{~m}^{3} / \mathrm{s}$ and $10^{4} \mathrm{~m}^{3} / \mathrm{s}$, respectively. The higher end of the volume rate range for Strombolian explosions is comparable to the volume rate of lava fountains. This result leads to the hypothesis that Strombolian explosions can produce a flow regime similar to that of lava fountains. In the case of Aso volcano, the volume flow rate is estimated to be $3 \times 10^{3}-2 \times 10^{4}$ $\mathrm{m}^{3} / \mathrm{s}$ when $D=10 \mathrm{~m}$ (considering an effective diameter in the conduit), $\varepsilon=0.45$, and $U_{\mathrm{g}}=20-160 \mathrm{~m} / \mathrm{s}$. Although this rate is somewhat lower than that of the lava fountains at Etna, it is relatively large among the volume rates of Strombolian explosions. Moreover, we can explain the ejection pulses revealed by recent observations using high-speed cameras at Stromboli volcano (Taddeucci et al. 2012; Gaudin et al. 2014). One
Strombolian explosion is composed of multiple short bursts (up to a hundred), not a single burst. As Taddeucci et al. (2012) proposed, these ejection pulses suggest that repeated and semicontinuous collapses of the liquid film surrounding long gas pockets could occur due to pressure fluctuations in the gas phase. This idea coincides with our hypothesis that a gas channel characterized as annular flow causes an explosion and subsequent gas emissions.

\section{Conclusion}

Strombolian explosions at Aso volcano in late April 2015 were observed by our monitoring system installed around the active crater: The system was composed of seismometers, low-frequency microphones, and a surveillance camera. As a result, characteristic VLP signals, eruption earthquake signals, and infrasound signals accompanying explosion events were obtained. We constrained the explosion depth and ascent velocity of a gas phase in the conduit using the differences in the seismoacoustic signal arrival times. The estimated depth was $<400 \mathrm{~m}$, which indicates that the depth was shallower than the large-sized crack. The ascent velocity of the gas phase was estimated to be $1-160 \mathrm{~m} / \mathrm{s}$. This velocity is too fast to assume the migration of a gas slug through the conduit. The ascent velocity of a slug from theoretical and experimental approaches cannot exceed $7.5 \mathrm{~m} / \mathrm{s}$ under the conditions present at Aso volcano. To explain our estimated values, we proposed a new concept for the Strombolian explosion-related gas flow dynamics in the conduit inspired by the steady two-phase flow regimes with large superficial gas velocities. This new model can lead to additional understanding of other phenomena associated with Strombolian explosions, e.g., ejection pulses. The future direction of this study will be to assess models other than the CF model and to explore both analog and numerical approaches for simulating the dynamics of unsteady flow in the conduit.

\section{List of symbols}

$c_{\text {air }}$
$c_{\text {con }}$
$D$
$d_{\exp }$
$d t$
$d_{\mathrm{VLP}}$
$E o$
$F r$
$g$
$h_{\mathrm{sH}}$
$h_{\mathrm{sL}}$

sound velocity in air sound velocity in the conduit diameter of the conduit explosion depth from the crater bottom combination of $\Delta t_{\mathrm{sH}-\mathrm{iH}}$ and $\Delta t_{\mathrm{sL}-\mathrm{iL}}$ VLP source depth

Eötvös number

Froude number gravitational acceleration height of KAF station from the crater floor height of UMA station from the crater floor 
$L_{\mathrm{i}} \quad$ total path length from the infrasound source to ACM station

$L_{\mathrm{i}}^{\prime} \quad$ propagation path length from the vent to ACM station

$L_{\mathrm{sH}} \quad$ propagation path length of eruption earthquake

$L_{\mathrm{sL}} \quad$ propagation path length of VLP seismic signal

$l_{\mathrm{sH}} \quad$ horizontal distance from the vent to KAF station

$l_{\mathrm{sL}} \quad$ horizontal distance from the vent to UMA station

$N_{\mathrm{f}} \quad$ dimensionless inverse viscosity

$t_{\mathrm{iH}} \quad$ arrival time of high-frequency infrasound signal at ACM station

$t_{\mathrm{iL}} \quad$ arrival time of low-frequency infrasound signal at ACM station

$t_{\mathrm{sH}} \quad$ arrival time of eruption earthquake signal at KAF station

$t_{\mathrm{sL}} \quad$ arrival time of VLP signal at UMA station

$u_{\text {asc }} \quad$ ascent velocity of the gas phase in the conduit

$U_{\mathrm{g}} \quad$ average gas velocity

$\frac{U_{\mathrm{g}}}{U_{\mathrm{g}}} \quad$ mean of average gas velocity $U_{\mathrm{g}}$ from a given depth to the surface

$U_{\text {sg }} \quad$ superficial gas velocity

$\bar{v}_{\mathrm{i}} \quad$ average sound velocity

$v_{\mathrm{P}} \quad$ P-wave velocity

$v_{\mathrm{S}} \quad \mathrm{S}$-wave velocity

$v_{\mathrm{sH}} \quad$ propagation velocity of eruption earthquake

$v_{\mathrm{SL}} \quad$ propagation velocity of VLP earthquake

$\Delta t_{\mathrm{iL}-\mathrm{iH}}$ time difference between low-frequency infrasound and high-frequency infrasound signals

$\Delta t_{\mathrm{sH}-\mathrm{iH}}$ time difference between eruption earthquake and high-frequency infrasound signals

$\Delta t_{\mathrm{sL}-\mathrm{iL}} \quad$ time difference between VLP earthquake and low-frequency infrasound signals

$\varepsilon \quad$ void fraction

$\mu \quad$ viscosity of liquid (magma)

$\rho_{1} \quad$ density of liquid (magma)

$\rho_{\mathrm{g}} \quad$ density of gas

$\sigma \quad$ surface tension of liquid (magma)

$\tau_{\text {asc }}$ rise time of the gas phase in the conduit from the VLP source to the explosion depth

$\tau_{\mathrm{iH}} \quad$ travel time for the high-frequency infrasound

$\tau_{\mathrm{iL}} \quad$ travel time for the low-frequency infrasound

$\tau_{\mathrm{sH}} \quad$ travel time for the eruption earthquake

$\tau_{\mathrm{sL}} \quad$ travel time for the VLP earthquake

\section{Abbreviations}

CF collapsing foam

PDF probability density function
RSD rise speed dependent

VLP very long period

\section{Additional files}

Additional file 1. Details of instruments and stations of our monitoring network.

Additional file 2. Supplementary explanation about how to determine the speed of sound in air and gas-gas mixture.

\section{Authors' contributions}

$\mathrm{Kl}$ performed the analysis in this study. $\mathrm{Kl}, \mathrm{AY}, \mathrm{TK}$, and TO contributed to the planning, data analysis, and interpretation in this study. TO, SY, and HI participated in the acquisition of seismic data. AY participated in the acquisition of acoustic data. All authors read and approved the final manuscript.

\section{Author details}

1 Department of Geophysics, Graduate School of Science, Kyoto University, Kitashirakawa Oiwake-cho, Sakyo-ku, Kyoto 606-8502, Japan. ${ }^{2}$ Aso Volcanological Laboratory, Kyoto University, 3028 Sakanashi, Ichinomiya-machi, Aso, Kumamoto 869-2611, Japan

\section{Acknowledgements}

We thank M. Iguchi and $\mathrm{H}$. Nakamichi for providing valuable advice and comments. We also thank the anonymous reviewers for their insightful comments that helped improve our paper.

\section{Competing interests}

The authors declare that they have no competing interests.

\section{Availability of data and materials}

The data that support the findings in the present study are available from the corresponding author upon a request.

Consent for publication

Not applicable.

Ethics approval and consent to participate

Not applicable.

Funding

The present study was financially supported by the Ministry of Education, Culture, Sports, Science and Technology of Japan under its Earthquake and Volcano Hazards Observation and Research Program.

\section{Publisher's Note}

Springer Nature remains neutral with regard to jurisdictional claims in published maps and institutional affiliations.

Received: 29 August 2018 Accepted: 24 January 2019

Published online: 02 February 2019

\footnotetext{
References

Allard P, Burton M, Muré F (2005) Spectroscopic evidence for a lava fountain driven by previously accumulated magmatic gas. Nature 433(7024):407410. https://doi.org/10.1038/nature03246

Allen RV (1978) Automatic earthquake recognition and timing from single traces. Bull Seismol Soc Am 68(5):1521-1532

Batchelor G (1967) An introduction to fluid mechanics. Cambridge University Press, New York, p 615
} 
Blackburn E, Wilson L, Sparks RJ (1976) Mechanisms and dynamics of Strombolian activity. J Geol Soc 132(4):429-440. https://doi.org/10.1144/gsjgs .132.4.0429

Braun T, Ripepe M (1993) Interaction of seismic and air waves recorded at Stromboli volcano. Geophys Res Lett 20(1):65-68. https://doi. org/10.1029/92GL02543

Capponi A, James MR, Lane SJ (2016) Gas slug ascent in a stratified magma: implications of flow organisation and instability for Strombolian eruption dynamics. Earth Planet Sci Lett 435:159-170. https://doi.org/10.1016/j. epsl.2015.12.028

Capponi A, Lane SJ, James MR (2017) The implications of gas slug ascent in a stratified magma for acoustic and ground deformation source mechanisms in Strombolian eruptions. Earth Planet Sci Lett 468:101-111. https ://doi.org/10.1016/j.epsl.2017.04.008

Chouet B, Dawson P, Ohminato T, Martini M, Saccorotti G, Giudicepietro F, De Luca G, Milana G, Scarpa R (2003) Source mechanisms of explosions at Stromboli volcano, Italy, determined from moment-tensor inversions of very-long-period data. J Geophys Res Solid Earth. https://doi. org/10.1029/2002jb001919

Del Bello E, Llewellin EW, Taddeucci J, Scarlato P, Lane SJ (2012) An analytical model for gas overpressure in slug-driven explosions: insights into Strombolian volcanic eruptions. J Geophys Res Solid Earth. https://doi. org/10.1029/2011jb008747

Del Bello E, Lane SJ, James MR, Llewellin EW, Taddeucci J, Scarlato P, Capponi A (2015) Viscous plugging can enhance and modulate explosivity of strombolian eruptions. Earth Planet Sci Lett 423:210-218. https://doi. org/10.1016/j.epsl.2015.04.034

Delle Donne D, Ripepe M (2012) High-frame rate thermal imagery of Strombolian explosions: implications for explosive and infrasonic source dynamics. J Geophys Res Solid Earth. https://doi.org/10.1029/2011jb008987

Gaudin D, Taddeucci J, Scarlato P, Moroni M, Freda C, Gaeta M, Palladino DM (2014) Pyroclast Tracking Velocimetry illuminates bomb ejection and explosion dynamics at Stromboli (Italy) and Yasur (Vanuatu) volcanoes. J Geophys Res Solid Earth 119(7):5384-5397. https://doi.org/10.1002/2014 B011095

Gaudin D, Taddeucci J, Scarlato P, Del Bello E, Ricci T, Orr T, Houghton B, Harris A, Rao S, Bucci A (2017) Integrating puffing and explosions in a general scheme for Strombolian-style activity. J Geophys Res Solid Earth 122(3):1860-1875. https://doi.org/10.1002/2016JB013707

Genco R, Ripepe M (2010) Inflation-deflation cycles revealed by tilt and seismic records at Stromboli volcano. Geophys Res Lett. https://doi. org/10.1029/2010gl042925

Genco R, Ripepe M, Marchetti E, Bonadonna C, Biass S (2014) Acoustic wavefield and Mach wave radiation of flashing arcs in strombolian explosion measured by image luminance. Geophys Res Lett 41(20):7135-7142. https://doi.org/10.1002/2014GL061597

Giordano D, Russell JK, Dingwell DB (2008) Viscosity of magmatic liquids: a model. Earth Planet Sci Lett 271:123-134. https://doi.org/10.1016/j. epsl.2008.03.038

Goto A, Ripepe M, Lacanna G (2014) Wideband acoustic records of explosive volcanic eruptions at stromboli: new insights on the explosive process and the acoustic source. Geophys Res Lett 41(11):3851-3857. https://doi. org/10.1002/2014GL060143

Gurioli L, Colo L, Bollasina A, Harris AJ, Whittington A, Ripepe M (2014) Dynamics of Strombolian explosions: inferences from field and laboratory studies of erupted bombs from Stromboli volcano. J Geophys Res Solid Earth 119(1):319-345. https://doi.org/10.1002/2013JB010355

Harris A, Ripepe M (2007) Synergy of multiple geophysical approaches to unravel explosive eruption conduit and source dynamics - a case study from Stromboli. Chem Der Erde Geochem 67(1):1-35. https://doi. org/10.1016/j.chemer.2007.01.003

Hewitt GF (2012) Churn and wispy annular flow regimes in vertical gas-liquid flows. Energy Fuels 26(7):4067-4077. https://doi.org/10.1021/ef3002422

Ichimura M, Yokoo A, Kagiyama T, Yoshikawa S, Inoue H (2018) Temporal variation in source location of continuous tremors before ash-gas emissions in January 2014 at Aso volcano, Japan. Earth Planets Space 70:125. https ://doi.org/10.1186/s40623-018-0895-4

James MR, Lane SJ, Houghton BF (2013) Unsteady explosive activity: Strombolian eruptions. In: Fagents SA, Gregg TKP, Lopes RMC (eds) Modeling volcanic processes: the physics and mathematics of volcanism. Cambridge University Press, Cambridge, pp 107-129
Japan Society of Mechanical Engineers (1986) JSME data book: heat transfer, 4th edn. Japan Society of Mechanical Engineers, Tokyo, p 329

Jaupart C, Vergniolle S (1988) Laboratory models of Hawaiian and Strombolian eruptions. Nature 331(6151):58-60. https://doi.org/10.1038/331058a0

Jaupart C, Vergniolle S (1989) The generation and collapse of a foam layer at the roof of a basaltic magma chamber. J Fluid Mech 203:347-380. https:// doi.org/10.1017/S0022112089001497

Kaneshima S, Kawakatsu H, Matsubayashi H, Sudo Y, Tsutsui T, Ohminato T, Ito H, Uhira K, Yamasamto H, Oikawa J (1996) Mechanism of phreatic eruptions at Aso volcano inferred from near-field broadband seismic observations. Science 273:642-644. https://doi.org/10.1126/science.273.5275.642

Kawakatsu H, Kaneshima S, Matsubayashi H, Ohminato T, Sudo Y, Tsutsui T, Uhira K, Yamasato H, Ito H, Legrand D (2000) Aso94: Aso seismic observation with broadband instruments. J Volcanol Geoth Res 101(1-2):129154. https://doi.org/10.1016/50377-0273(00)00166-9

Lieth J, Hort M (2016) Slug ascent and associated stresses during strombolian activity with non-Newtonian rheology. J Geophys Res Solid Earth 121(7):4923-4942. https://doi.org/10.1002/2015JB012683

Llewellin E, Del Bello E, Taddeucci J, Scarlato P, Lane S (2011) The thickness of the falling film of liquid around a Taylor bubble. Proc R Soc A. https://doi. org/10.1098/rspa.2011.0476

Marchetti E, Ripepe M, Delle Donne D, Genco R, Finizola A, Garaebiti E (2013) Blast waves from violent explosive activity at Yasur volcano, Vanuatu. Geophys Res Lett 40(22):5838-5843. https://doi.org/10.1002/2013GL0579 00

Morrissey M, Chouet B (2001) Trends in long-period seismicity related to magmatic fluid compositions. J Volcanol Geoth Res 108(1):265-281. https ://doi.org/10.1016/S0377-0273(00)00290-0

Nabyl A, Dorel J, Lardy M (1997) A comparative study of low-frequency seismic signals recorded at Stromboli volcano, Italy, and at Yasur volcano, Vanuatu. NZ J Geol Geophys 40(4):549-558. https://doi.org/10.1080/00288 306.1997.9514783

Namiki A, Tanaka Y, Yokoyama T (2018) Physical characteristics of scoriae and ash from 2014-2015 eruption of Aso Volcano, Japan. Earth Planets Space 70(1):147. https://doi.org/10.1186/s40623-018-0914-5

National Institute of Advanced Industrial Science and Technology (2015) Volcanic gas compositional change of Nakadake, Aso volcano. The 131th Japan Meteorological Agency's Volcanic Eruption Prediction Liaison Council report

Ono K, Watanabe K, Hoshizumi H, Takada H, Ikebe S (1995) Ash eruption of Nakadake Volcano, Aso caldera, and its products. Bull Volcanol Soc Jpn 40(3):133-151. https://doi.org/10.18940/kazan.40.3_133

Patrick MR (2007) Dynamics of Strombolian ash plumes from thermal video: motion, morphology, and air entrainment. J Geophys Res. https://doi. org/10.1029/2006jb004387

Patrick MR, Harris AJ, Ripepe M, Dehn J, Rothery DA, Calvari S (2007) Strombolian explosive styles and source conditions: insights from thermal (FLIR) video. Bull Volc 69(7):769-784. https://doi.org/10.1007/s0044 5-006-0107-0

Pioli L, Bonadonna C, Azzopardi BJ, Phillips JC, Ripepe M (2012) Experimental constraints on the outgassing dynamics of basaltic magmas. J Geophys Res Solid Earth. https://doi.org/10.1029/2011jb008392

Pushkina O, Sorokin YL (1969) Breakdown of liquid film motion in vertical tubes. Heat Transfer Sov Res 1(5):56-64

Ripepe M, Ciliberto S, Della Schiava M (2001) Time constraints for modeling source dynamics of volcanic explosions at Stromboli. J Geophys Res 106(B5):8713-8727. https://doi.org/10.1029/2000JB900374

Rowe C, Aster R, Kyle P, Dibble R, Schlue J (2000) Seismic and acoustic observations at mount Erebus volcano, Ross island, Antarctica, 1994-1998. J Volcanol Geoth Res 101(1):105-128. https://doi.org/10.1016/S0377 $-0273(00) 00170-0$

Seyfried R, Freundt A (2000) Experiments on conduit flow and eruption behavior of basaltic volcanic eruptions. J Geophys Res Solid Earth 105(B10):23727-23740. https://doi.org/10.1029/2000JB900096

Shinohara H, Yokoo A, Kazahaya R (2018) Variation of volcanic gas composition during the eruptive period in 2014-2015 at Nakadake crater, Aso volcano, Japan. Earth Planets Space 70(1):151. https://doi.org/10.1186/ s40623-018-0919-0

Sudo Y, Kong L (2001) Three-dimensional seismic velocity structure beneath Aso volcano, Kyushu, Japan. Bull Volc 63(5):326-344. https://doi. org/10.1007/s004450100145 
Taddeucci J, Scarlato P, Capponi A, Del Bello E, Cimarelli C, Palladino DM, Kueppers U (2012) High-speed imaging of strombolian explosions: the ejection velocity of pyroclasts. Geophys Res Lett. https://doi. org/10.1029/2011gl050404

Taitel Y, Bornea D, Dukler AE (1980) Modelling flow pattern transitions for steady upward gas-liquid flow in vertical tubes. AIChE J 26(3):345-354. https://doi.org/10.1002/aic.690260304

Tsutsui T, Sudo Y, Mori T, Katsumata K, Tanaka S, Oikawa J, Tomatsu T, Matsuwo N, Matsushima T, Miyamachi H, Nishi K, Fujiwara Y, Hiramatsu H (2003) 3-D seismic velocity structure beneath the edifice of central cones of Aso volcano. Bull Volcanol Soc Jpn 48(3):293-307. https://doi.org/10.18940/ kazan.48.3_293

Ulivieri G, Ripepe M, Marchetti E (2013) Infrasound reveals transition to oscillatory discharge regime during lava fountaining: implication for early warning. Geophys Res Lett 40(12):3008-3013. https://doi.org/10.1002/ grl.50592

Vergniolle S, Brandeis G (1994) Origin of the sound generated by Strombolian explosions. Geophys Res Lett 21(18):1959-1962. https://doi. org/10.1029/94GL01286

Vergniolle S, Brandeis G (1996) Strombolian explosions: 1. A large bubble breaking at the surface of a lava column as a source of sound. J Geophys Res Solid Earth 101(B9):20433-20447. https://doi.org/10.1029/96jb01178

Vergniolle S, Ripepe M (2008) From Strombolian explosions to fire fountains at Etna Volcano (Italy): what do we learn from acoustic measurements? In: Lane SJ, Gilbert JS (eds) Fluid motions in volcanic conduits: a source of seismic and acoustic signals, vol 307. Geological Society, London, pp 103-124. https://doi.org/10.1144/sp307.7

Viana F, Pardo R, Yánez R, Trallero JL, Joseph DD (2003) Universal correlation for the rise velocity of long gas bubbles in round pipes. J Fluid Mech 494:379-398. https://doi.org/10.1017/S0022112003006165

Wagner W, Pruß A (2002) The IAPWS formulation 1995 for the thermodynamic properties of ordinary water substance for general and scientific use. J Phys Chem Ref Data 31(2):387-535. https://doi.org/10.1063/1.1461829
Walker D, Mullins O (1981) Surface tension of natural silicate melts from 1,200-1,500 C and implications for melt structure. Contrib Miner Petrol 76(4):455-462. https://doi.org/10.1007/BF00371487

Wilson L (1980) Relationships between pressure, volatile content and ejecta velocity in three types of volcanic explosion. J Volcanol Geoth Res 8(2-4):297-313. https://doi.org/10.1016/0377-0273(80)90110-9

Wilson L, Head JW III (1981) Ascent and eruption of basaltic magma on the Earth and Moon. J Geophys Res Solid Earth 86(B4):2971-3001. https://doi. org/10.1029/JB086iB04p02971

Yamamoto M (2005) Volcanic fluid system inferred from broadband seismic signals. Ph.D. thesis, Earthquake Research Institute, The University of Tokyo

Yamamoto M, Kawakatsu H, Kaneshima S, Mori T, Tsutsui T, Sudo Y, Morita Y (1999) Detection of a crack-like conduit beneath the active crater at Aso volcano Japan. Geophys Res Lett 26(24):3677-3680. https://doi. org/10.1029/1999GL005395

Yokoo A, Miyabuchi Y (2015) Eruption at the Nakadake 1st crater of Aso volcano started in November 2014. Bull Volcanol Soc Jpn 60(2):275-278. https://doi.org/10.18940/kazan.60.2_275

Yokoo A, Ishii K, Ohkura T, Kim K (2019) Monochromatic infrasound waves observed during the 2014-2015 eruption of Aso volcano, Japan. Earth Planets Space 71:12. https://doi.org/10.1186/s40623-019-0993-y

Yoshikawa S, Sudo Y (2004) Volcanic activity and surface temperature variation of crater lake in Naka-dake crater at Aso volcano. Ann Disas Prev Res Inst Kyoto Univ 47(B):803-807

Zobin VM, Sudo Y (2017) Source properties of Strombolian explosions at Aso volcano, Japan, derived from seismic signals. Phys Earth Planet Inter 268:1-10. https://doi.org/10.1016/j.pepi.2017.05.002

\section{Submit your manuscript to a SpringerOpen ${ }^{\circ}$ journal and benefit from:}

- Convenient online submission

- Rigorous peer review

- Open access: articles freely available online

- High visibility within the field

- Retaining the copyright to your article

Submit your next manuscript at $\boldsymbol{\nabla}$ springeropen.com 